\title{
Nota para estudos teórico-históricos do fenômeno da heresia
}

\author{
Note to theoretical and historical studies on the phenomenon of heresy
}

\author{
Juvenal Savian Filho ${ }^{1}$
}

\section{RESUMO}

O objetivo desta nota é reunir alguns elementos que podem contribuir para um estudo não apenas teórico como também histórico do fenômeno a que se denomina heresia. Ela se estrutura em duas partes: (i) um levantamento de dados histórico-semânticos que permitem (ii) uma investigação do que seria, em termos fenomenológicos, a essência da heresia. Seu fundamento é o artigo $O$ que é heresia?, de Karl Rahner, autor de grande relevância para a heresiologia no século XX, embora pouco estudado nos meios acadêmicos.

Palavras-chave: Heresia. Heterodoxia. Ortodoxia. Verdade. Rahner

\section{ABSTRACT}

This note aims to bring together some elements that can contribute to a study not only theoretical but also historical about the so-called phenomenon of the heresy. It is structured in two parts: (i) a collection of some historical and semantic aspects that found (ii) an investigation of what would be, in phenomenological terms, the essence of heresy. It is foundend on the article What is heresy?, writted by Karl Rahner, author of great relevance to heresiology in the twentieth century, though little evoqued in academic circles.

Keyword: Heresy. Heterodoxy. Ortodoxy. Truth. Rahner..

Esta nota se constrói segundo um método fenomenológico, quer dizer, centrado no clareamento de essência ou conjunto de características sem as quais o fenômeno deixa de manifestar o sentido que é seu. Especificamente no tocante à ideia ou essência da heresia, trata-se de trazer à luz as características que permitem identificar uma experiência como herética. Assim como fenomenologicamente se pode clarear, por exemplo, a essência de fenômenos como "emoção" e "sentimento", entre outros pressupostos pela Psicologia, ou

\footnotetext{
${ }^{1}$ Professor do Departamento de Filosofia da Universidade Federal de São Paulo. e-mail:jsfilho@usp.br
} 
"lei", "direito" e "dever", entre outros pressupostos pelo Direito, também é possível clarear o fenômeno da heresia, cuja ideia é pressuposta pela História, Filosofia e Teologia ${ }^{2}$. O ganho dessa abordagem se evidencia sobretudo quando se observa que ela permite avaliar a validade e a adequação da compreensão de fenômenos identificados ao longo de diferentes processos históricos.

Algumas informações gerais, de caráter histórico-semântico, serão levantadas inicialmente, para, na sequência, tomar-se o artigo $O$ que é heresia?, escrito em 1962 pelo teólogo alemão Karl Rahner (1904-1984), como base para investigar a essência desse fenômeno (RAHNER, 1962, p. 527-576) ${ }^{3}$.

\section{Dados histórico-semânticos}

Na caracterização da heresia, um dado a ser considerado é que o termo heresia designou diferentes fenômenos em diferentes momentos. Na Antiguidade, ele não se referia praticamente a nada de semelhante ao que na Antiguidade Tardia, na Idade Média, na Modernidade e na Contemporaneidade se costumou referir por esse nome. $O$ antigo termo grego haíresis designava, de modo geral, a ideia de uma tomada (tomada de uma cidade; tomada de posição). Assim, por exemplo, fala-se de tomada de uma cidade em Heródoto (Histórias 4, 1) e Tucídides (História da Guerra do Peloponeso 2, 58), mas também de tomada de posição ou de escolha (Heródoto 1, 1; Tucídides 2, 61). Em Platão, o termo se impõe como referência a uma escolha (Górgias 245b, Teeteto 196c, Sofista 265), a uma preferência ou gosto particular, desígnio, projeto (Górgias 513a, Fedro 256c). Em Políbio (Histórias 2, 61, 9), o termo chega a ser associado à função escolhida por eleição ou à magistratura. Aos poucos, o sentido começa a fixar-se em torno da ideia de preferência por determinado pensamento, escola filosófica (Políbio 5, 93, 8; Sexto Empírico, Hipotiposes pirrônicas 41, 7), escola literária (Dionísio de Halicarnasso, Antiguidades romanas 5, 134) e escola médica (Sexto Empírico 55, 5). É com esse sentido de escola, grupo ou tendência intelectual que o termo aparece no Novo Testamento, para designar grupos religiosos considerados sectários (destoantes da posição da maioria), como se observa em Atos dos Apóstolos 5, 17 (referência aos saduceus) e em Atos 15,$5 ; 26,5$ (referência aos fariseus).

\footnotetext{
${ }^{2}$ Enquanto às "ciências" ou aos "saberes" cabe explicar os fenômenos (do ponto de vista de sua gênese, por exemplo), à orientação fenomenológica cabe descrever a essência dos fenômenos precisamente no modo como eles se apresentam para a consciência (na linha das idealidades que operam nas expressões fenomênicas e para além da tensão entre historicidade e universalidade).

${ }^{3}$ Há uma tradução francesa em Écrits théologiques de 1970 e também uma tradução espanhola em Escritos de teologia de 1964.
} 
A variedade de fenômenos enfeixados sob o termo heresia mostra-se, então, bastante grande já em uma primeira e rápida análise semântica. Parece possível afirmar, no entanto, que aos poucos uma ideia passou a destacar-se como conteúdo essencial da heresia: no modo como formulou Dionísio de Halicarnasso (final da era pré-cristã, portanto), a heresia consistia fundamentalmente no motivo de uma escolha ou numa frase que exprime uma tomada de posição (Antiguidades Romanas 3, 10), sentido que reaparece na passagem do século II ao III, com Díon Cássio (História de Roma 74, 17).

Antes de aparecer em Díon Cássio, o termo heresia parece ter fixado o significado de frase que exprime uma tomada de posição já nos textos do Novo Testamento (KERN, 2004, p. 815-816). O próprio cristianismo, nos Atos dos Apóstolos, é considerado uma "facção" nascida no judaísmo ("heresia dos nazareus", nazoraíon hairéseos - Atos 24, 5; 28, 22). Segundo Paulo, as tensões e divisões internas das comunidades cristãs eram heresias ou cismas (Gálatas 5 , 20; 1Coríntios 11, 18s), bem como eram heresias as falsas doutrinas (1Timóteo 1, 3-11; 4, 1-5; 2Timóteo 2, 14). Na passagem do século I ao II, Inácio de Antioquia chama o docetismo de heterodoxia (Epístola aos Magnésios 8, 1), associando esse termo à ideia de heresia e marcando, assim, um campo semântico que será de grande importância nos séculos seguintes: heresia relaciona-se com heterodoxia e, portanto, pode-se acrescentar, com ortodoxia. Segundo Inácio, heresia significa separação, autocolocação como "outro" ou héteros em relação à opinião ou dóxa majoritária (Epístola aos Efésios 6, 2; Epístola aos Trálios 6, 1). Ainda no século II, Justino de Roma escreveu uma obra intitulada Syntagma (hoje perdida) contra todas as heresias por ele conhecidas; essa obra influenciará os catálogos de heresia que circularão na sequência. Outra "suma" será escrita no século II, por Irineu de Lion, contra os hereges gnósticos, os quais, segundo o vocabulário de Tertuliano (séc. II-III), autodesqualificavam-se por não conservarem a transmissão ou tradição da fé apostólica. Consagrava-se, assim, a ideia ou o conceito de heresia como heterodoxia, quer dizer, como opinião, posição ou pensamento que destoa da posição majoritária ou tradicional. O contexto é cristão, obviamente, e o uso do termo, a partir do século III, parece reservar-se, em seu sentido técnico, ao vocabulário cristão: ainda que se possa empregar o termo heresia em um sentido amplo e nos contextos mais variados (sempre para designar uma posição destoante no interior de uma forma de pensar hegemônica), nenhuma forma de discurso dará tanta atenção à heresia como o discurso cristão.

De um ponto de vista quantitativo, a catalogação de heresias parece atingir o ápice durante a Antiguidade Tardia, com a obra de título sugestivo Panarion (Remédios), de Epifânio de Salamina (séc. IV-V), que escreve algo como uma "história universal" e repertoria oitenta heresias de antes e depois de Cristo. Pouco tempo depois, Agostinho de Hipona, em seu combate ao maniqueísmo, ao pelagianismo e ao donatismo faz recurso ao poder civil. Sabe-se que já em 385 foi executado pela primeira vez um herético: Prisciliano e seus companheiros, na cidade de Tréveris. Nos séculos XII e XIII, heréticos são os cátaros, os valdenses, os albigenses; e, no século XIV, John Hus e John Wycliff, entre outros. No século 
XVI, os católicos chamarão os Reformadores de heréticos, enquanto os Reformadores chamarão de heréticos os "papistas" ou católicos. Católicos e protestantes, por sua vez, unem-se para condenar como heréticos os anabatistas e os antitrinitários, cujo maior exemplo é certamente Miguel de Servet (1511-1553), executado pela Inquisição Protestante em Genebra. Na Modernidade, sob influência do humanismo, do pietismo e do ideal iluminista, a acusação de heresia se volta contra os próprios cristãos: o reformista alemão Sebastian Franck (1499-1542), por exemplo, chama de herética toda ortodoxia estabelecida; e o luterano alemão Gottfried Arnold (1666-1714) manifesta uma explícita simpatia pelas heresias em contraposição com as doutrinas das instituições eclesiásticas.

A essa breve apresentação da história do termo heresia e do conceito que a ele foi associado historicamente (o de heterodoxia, basicamente) é adequado acrescentar um comentário também histórico, concernente à ideia ou conceito de ortodoxia: em seu sentido de opinião ou posição correta em matéria de fé (órthos, correto, e dóxa, opinião, fé, glória), esse conceito mostra-se posterior ao de heresia e ao de heterodoxia. Ele parece, aliás, ter sido formulado depois dos embates com as heresias. Com efeito, de um ponto de vista doutrinal, o conceito de ortodoxia (nem sempre nomeado) começa a ser empregado nos concílios de Niceia I (325), Constantinopla I (381), Éfeso I (431) e Calcedônia (451), tomando forma no que talvez tenha sido o primeiro documento que sintetiza os princípios fundamentais da "fé ortodoxa", o Código de Justiniano, de 529. Um século depois, a obra A fé ortodoxa, de João Damasceno (676-749), já apresenta de maneira "clássica" a ideia de um conjunto doutrinal que exprime a fé correta (LOSSKY, 2004, p. 1299-1300). Dessa perspectiva, parece mesmo adequado pressupor que as heresias não foram simplesmente "construídas" ou "inventadas" por ortodoxos ou adeptos de uma ortodoxia, mas que a ortodoxia foi explicitada com base no confronto com as heresias ${ }^{4}$.

Esse dado é de grande significação (não apenas histórica, mas também teórica), pois aponta para algo interno à dinâmica da própria fé cristã: vista da perspectiva do ato subjetivo (ato livre de um sujeito), a fé é uma adesão ao mistério divino em uma relação interpessoal (entre a pessoa que crê e a "pessoa" do ser divino; também entre pessoas crentes); mas esse ato subjetivo de fé exprime-se por meio de conteúdos compreensíveis (racionais/razoáveis), aos quais também se chama de "fé objetiva" ou de "artigos de fé". A ortodoxia, assim, estaria ligada à formulação dos artigos da fé objetiva com o intuito de exprimir a fé subjetiva. Ao exprimir a fé subjetiva, a fé objetiva é considerada "boa" ou "adequada" se mantém fidelidade àquilo que foi transmitido pelos apóstolos de Jesus e seus

\footnotetext{
${ }^{4}$ Fazer essa afirmação não significa afirmar que antes das heresias não havia "ortodoxia”. No sentido cristão, fixado para o uso do termo, as ocorrências no Novo Testamento são suficientes para mostrar que havia já uma "ortodoxia", ainda que mínima, em contraponto com a qual as heresias eram identificadas. Tal "ortodoxia" era constituída principalmente por conteúdos referentes à pessoa divino-humana de Jesus Cristo (por exemplo, a condenação joanina do docetismo já em 1João 4, 2-3 e 2João 7). No entanto, a despeito de haver uma "ortodoxia" de fato, o conceito de ortodoxia não parece ter sido expresso (com seu termo correspondente) antes dos séculos IV-VI. Dessa perspectiva, parece possível combinar a tese de que as heresias pré-existem à ortodoxia (vista como conceito) com a tese de que antes das heresias havia uma "ortodoxia" (de fato e ainda que mínima). A respeito dessa problemática (BAUER, 1971; KÖSTENBERGER; KRUGER, 2010).
} 
sucessores, os membros da comunidade dos crentes. Essa dinâmica aparece já no Novo Testamento, principalmente em um trecho bastante representativo como o de 1 Coríntios 11, 19, no qual se lê que é mesmo necessário haver hairéseis (heresias/facções) entre os fieis, para pô-los à prova. Daqui se pode certamente tomar um ponto de partida para investigar a essência do fenômeno da heresia.

\section{A essência da heresia}

Buscar a essência da heresia ${ }^{5}$ é uma tarefa indispensável se se deseja identificar com o máximo possível de adequação o fenômeno que lhe corresponde nas diferentes temporalidades. Por analogia, um psicólogo que não tenha clareza sobre a essência da emoção (das vivências/experiências que recebem este nome) corre o risco de não identificar as emoções de seu paciente ou de mal visá-las; e um jurista pode passar ao largo da relação entre lei e justiça caso não conheça com clareza a essência de ambas ${ }^{6}$. Assim também, o filósofo, o historiador e o teólogo, caso não tenham clareza sobre a essência dos fenômenos heréticos, podem não os identificar adequadamente ou não os abordar na complexidade que eles envolvem. No caso da pesquisa histórica, espera-se, obviamente, que a definição de heresia seja dada com base nos documentos-fontes e não pela retroprojeção de alguma "essência" atemporal. Mas, em termos fenomenológicos, buscar a essência de um fenômeno não significa operar com essências atemporais; se há atemporalidade das essências, ela não se encontra do lado de uma pretensa identidade estática dos fenômenos mesmos, e sim do seu modo de aparecer para a consciência ${ }^{7}$. Clarear, portanto, as características com que o fenômeno da heresia aparece para nós é uma atividade de grande ganho, sobretudo porque permite confrontar as características que surgem de uma análise objetivo-subjetiva

\footnotetext{
${ }^{5}$ Considerando-se aqui o sentido fenomenológico de "essência" (o das características fundamentais do modo como algo aparece para a consciência) e não o sentido tradicional (da essência como algo que daria uma identidade estática para um ente). A referência fundamental para a compreensão da ideia fenomenológica de essência (na tensão entre historicidade das expressões e idealidade dos conteúdos universais) é o trabalho de Edmund Husserl, registrado principalmente em duas obras emblemáticas: as Investigações lógicas e o volume I das Ideias para uma fenomenologia pura e uma filosofia fenomenológica.

${ }^{6}$ Respeitando o dado óbvio de que a expressão dos fenômenos é, em grande medida, construída historicamente, a orientação fenomenológica que busca essências pretende fazer vir à tona o que há de universal e necessário por trás das contingências das expressões históricas. Por exemplo, ainda que uma comunidade indígena, um ocidental europeu ou um oriental japonês deem expressões diferentes para a vivência da raiva, da alegria, do amor etc., hoje é bastante defensável a visão de que todos esses representantes de culturas diferentes operam com constantes universais na vivência das paixões. Chegar a tais constantes equivaleria clarear essência de cada paixão.

${ }^{7}$ Toma-se o termo consciência, aqui, no sentido amplo da possibilidade humana de perceber unidades de sentido. Não se trata, porém, de conceber a consciência como mero receptáculo passivo ou "depósito" de informações, mas como uma relação que cada polo cognoscente (cada sujeito) estabelece com os objetos que se lhe apresentam. A presença de qualquer unidade de sentido que se manifesta na experiência não ocupa a consciência ao modo de um objeto que invade um espaço vazio; ao contrário, tal presença se dá à medida que a consciência a acolhe e, de certo modo, identifica-se com ela, de maneira que conhecer não será apenas reproduzir algo exterior, mas um voltar-se da consciência sobre si mesma.
} 
(centrada no objeto "heresia" tal como ele se doa ao sujeito do conhecimento) com as características que talvez costumemos procurar nos fenômenos heréticos segundo hábitos mentais não tematizados ou mesmo acríticos.

Nesse trabalho de busca da essência da heresia, tomar como ponto de partida a distinção entre a fé subjetiva e a fé objetiva ${ }^{8}$ mostra-se não apenas adequado como imprescindível, pois é em algo como um descompasso da fé objetiva de um herege com a fé objetiva ortodoxa (na articulação das expressões de fé com a substância da fé subjetiva) que a essência do fenômeno da heresia parece deixar-se captar. É precisamente nessa direção que vai o artigo de Karl Rahner como contribuição para uma "ciência de essência" da heresia. Aliás, Rahner foi formado em grande medida na escola fenomenológica de Edmund Husserl, visto ter sido aluno de Martin Heidegger.

Ao expor o descompasso típico da heresia, Rahner faz ver que a característica essencial desse fenômeno está em ter significado apenas por contraponto a um "ethos da verdade" típico do cristianismo. Como ethos ou como modo de ser, a consciência cristã de sua relação com a verdade comporta dois momentos: (i) a consciência de que em um ponto bastante determinado do espaço e do tempo e em seres humanos também bastante determinados (e apenas por meio desses seres humanos) ocorreu, como acontecimento, uma revelação da verdade do mistério divino; (ii) a consciência de que essa verdade possui significação salvadora, quer dizer, significação que introduz na vida divina mesma e resgata os seres humanos de seu afastamento de Deus. Numa palavra, a consciência cristã da verdade equivale à consciência da historicidade de uma verdade absoluta, a qual, por si só, já é de significação salvadora. Ora, se a heresia - investigada em seu modo de aparecer à consciência cristã e confirmada pelos documentos de diferentes temporalidades - só revela seu sentido por contraponto a tal ethos tipicamente cristão, então a essência, a ideia ou o eidos da heresia estaria em prejudicar a integridade da consciência da historicidade da verdade absoluta e em pôr em risco o caráter salvador da adesão a essa verdade.

Segundo a definição tradicional (vinda da doutrina católica expressa no Concílio Vaticano I e assumida pelos mais destacados teólogos protestantes, entre eles os autores da Theologische Realenzylopädie), herege é "quem, depois do batismo e conservando o nome de cristão (retinendo nomen christianum), nega obstinadamente ou põe em dúvida uma das verdades nas quais se deve crer"9. Diferentemente do apóstata (que abandona a fé), o herege pretende manter a fé cristã (retinendo nomen christianum), mas prejudica a consciência do "acontecimento cristão" e a salvação possibilitada pela relação nascida dessa consciência.

\footnotetext{
${ }^{8}$ Isto é, a distinção entre a fé como ato de adesão livre de um sujeito à "substância da fé" (o mistério divino que atrai o crente e que é por ele experienciado como presença) e a fé como conjunto de expressões da substância da fé.

${ }^{9}$ Essa definição era dada pelo Código de Direito Canônico dos tempos de Rahner, no cânon 1325, 2. Hoje, com o atual Código de Direito Canônico (de 1983), a mesma definição é dada no cânon 751.
} 
Essa definição faz ver, logo de saída, a complexidade envolvida na caracterização da heresia da perspectiva do ato subjetivo da fé: o herege pode ser alguém dotado de sinceridade e que, discordando de aspectos parciais da fé objetiva (a fé vista como conjunto de artigos a crer), não pretende necessariamente afastar-se do seu conjunto, menos ainda da substância da fé. Há, segundo Rahner, uma unidade e totalidade da realidade que salva (o mistério divino) e, com ela, a unidade dos artigos de fé. Formalmente, é o próprio Deus que garante a verdade dos artigos de fé; e os artigos de fé, por sua vez, são formulados ou expressos pela Igreja entendida como comunidade dos que creem. No entanto, o herege vive a ambiguidade de escolher o todo ou a unidade do mistério salvador, conservando o nome de cristão, mas também escolhendo, no entanto, apenas parte da fé objetiva. Sua ambiguidade é existencial e indefinível, flutuante, pois se dá em um devir inconcluso. Analisado, porém, até sua raiz, o ato herético atinge também a dimensão subjetiva da adesão a Deus, pois a negação de um aspecto objetivo contradiz a autoridade formal do ser divino que se revela, mas convém considerar que o herege não deseja chegar a essa profundidade. Em geral, os hereges, por excesso de intelectualismo, desejam outras expressões (heterodoxas) para tal profundidade. Como diz Rahner, as heresias não são apenas ideias nascidas de erros e estupidezas; elas nascem de buscas inteligentes de compreensão e enraízam-se em experiências autênticas do mistério divino.

O descompasso na articulação da fé objetiva com a expressão majoritária da substância da fé não é algo que existiu apenas na história do cristianismo; é um fenômeno do qual dificilmente se escapa na Contemporaneidade: haveria, segundo Rahner, uma "heresia criptógama", sutil ou disfarçada, em nossos dias, pois, mesmo sem desejar refletidamente, a maioria dos cristãos nega sempre algum aspecto do conjunto das verdades de fé. Em outras palavras, mesmo sem rechaçar ou negar conscientemente algum conteúdo da fé objetiva, os cristãos são levados, quase sempre sem perceber, a tal rechaço ou negação. Como exemplo, Rahner menciona a idolatria do corpo ou a "mística" do esporte e da saúde física como orientadoras principais da vida humana, em detrimento da interioridade. Ou ainda, a prerrogativa da economia como critério de explicação e organização da vida, quando, para um crente, tal critério deveria ser o mistério divino reconhecido precisamente como mistério. Em outras palavras, a vida tal como se encontra estruturada leva a uma negação prática (não necessariamente tematizada, refletida) da verdade da fé mesmo por parte daqueles que querem manter-se fieis à substância da fé e às suas expressões ortodoxas.

Essa experiência ambígua faz sobressair ainda mais a complexidade do fenômeno da heresia, pois, embora sua essência possa ser associada ao descompasso já mencionado, tal descompasso pode insinuar-se mesmo na vivência mais autêntica da fé. No limite, tal fenômeno nasce da própria dinâmica da fé, que exige um trabalho constante e interminável de busca de fidelidade expressiva ao conteúdo ou substância da fé, fidelidade esta que, dada a limitação humana, pode variar em grau e qualidade. Como se diz em 1Coríntios 11, 19, é "necessário" ou "bom" haver heresias entre os fieis, para pô-los à prova. No entanto, dado o 
ethos cristão da verdade, tal trabalho de busca de fidelidade deve ser feito sem cessar. Óbvia e desafortunadamente, abre-se espaço para abusos de grupos hegemônicos, autoridades, posturas "subjetivistas", "objetivistas" etc.; e a História está repleta de casos que provam tais abusos. Longe, porém, de justificá-los, trata-se de perceber a vinculação estreita (e vital para o cristianismo) entre o ethos da verdade e o eidos da heresia. Nas diferentes temporalidades, os cristãos não podem abrir mão do debate em torno da fé objetiva, sob o risco de atentar contra a autoridade formal do próprio ser divino que se revela e de "fechar" aos fieis o acesso à salvação (ainda que o mistério da salvação seja infinitamente maior do que o retrato dele feito pelas expressões de fé, operando aliás para além dos limites dessas expressões).

Dessa perspectiva, Rahner destaca outro elemento na compreensão atual da heresia, bastante significativo não apenas para a Filosofia e a Teologia, mas também para a historiografia da heresia. Certamente sob a influência de Heidegger, Rahner lembra a peculiaridade da situação espiritual (intelecto e liberdade) do ser humano na Contemporaneidade: vive-se uma exuberância inabarcável da experiência, do saber e das ciências. A vastidão dos resultados da atividade de conhecer e das possibilidades de agir faz que o ser humano, hoje, não possa pretender dominar completamente nenhum ramo do conhecimento (um matemático não tem a possibilidade de saber tudo sobre a Matemática, assim como um biólogo não pode saber tudo sobre Biologia). Por essa razão, a existência humana, sob a perspectiva do a priori do pensamento, da decisão e da ação (condição espiritual), está determinada por aquilo que não se sabe e por aquilo pelo que não se pode ser responsável. Tal situação espiritual dificulta entender o ethos cristão da verdade, levando a algo como uma simpatia pela diversidade e pela heresia (entendendo-a como algo "natural" e "bom", praticamente um sinal de "democracia" do pensamento).

Antes da Modernidade, porém, essa situação espiritual não existia. É certo que o ser humano nem sempre viveu apenas do que sabia ou do que havia tematizado, mas é difícil negar que antes dos padrões modernos de conhecimento as forças espirituais (intelecto e liberdade) eram, digamos, dados objetivos e conhecidos: acreditava-se na raça, no solo, nos vínculos etc., realidades que, como diz Rahner, mostravam-se na inocência de terem sido criadas por Deus. Os humanos podiam apreender as realidades e conhecê-las, tomar posição a seu respeito, compensá-las umas com as outras e organizá-las em um sistema pelo qual eles se sabiam responsáveis. O que não era conhecido dessa maneira sequer tocava essencialmente o âmbito de sua existência espiritual. O que era conhecido era uma porção abarcável do que se podia conhecer; e o que o ser humano não sabia também não ocorria no conjunto de sua vida. Nesse quadro espiritual, era compreensível a atenção aguda ao fenômeno da heresia; o debate sobre a fé objetiva era cotidiano, fazia parte do modo de vida geral. Por contraposição, na Contemporaneidade, o que cada ser humano abarca temporal e fisiologicamente não coincide e não pode coincidir com o que "é sabido" (por outros) em geral. O saber, hoje, não é um saber relativo a fatos indiscutíveis, embora os possuidores de saber, a partir do século XIX, se entreguem aos resultados parciais das ciências com muito 
mais ingenuidade do que um teólogo do século XIII fazia com a Bíblia. O saber não administrado (não sistematizado) e sobre o qual atualmente ninguém responde tornou-se uma massa amorfa de resultados científicos, teoremas, hipóteses, postulados, sonhos e utopias, tendências unilaterais e autorreferentes, impulsos obscuros; e nessa massa operam tanto a habilidade como a estupidez, a inspiração divina e as forças do obscurantismo. Com expressões impactantes desse tipo, Rahner lembra que nossos hábitos cognitivos estão formados de maneira a quase tornar impossível o conhecimento histórico. $\mathrm{O}$ mundo do espírito, hoje, é o mundo criado humanamente, sem a atitude da contemplação do "mundo pelo mundo" e resultando em técnicas, invenções, instituições sociais, direcionamentos da atenção por meio da publicidade e de mil outras realidades semelhantes. Essas configurações da atenção constituem-se sempre em ilhas de sentido no meio da massa amorfa que a atitude cognitiva moderno-contemporânea produz.

Em tal quadro, é enorme o risco de permanecer insensível ao modo como o fenômeno da heresia apareceu historicamente. Seja para identificá-lo em diferentes temporalidades, seja para pensá-lo nos dias de hoje, é quase inescapável a tendência de projetar sobre ele os hábitos mentais de que se dispõe na atualidade. É apenas por um esforço de contraposição e de esclarecimento de essências que Rahner crê ser possível aproximar-se de maneira mais autêntica da complexidade que constitui esse fenômeno. Não é por acaso que, falando de dentro de um contexto eclesial, Rahner afirma sem receios que sempre deverá haver heresias (ainda que, do ponto de vista da história da salvação, esse deverá existe sem prejuízo da crença de que algo desse tipo não precisaria existir). Trata-se de um deverá que merece ser pensado no interior de uma ética comunitária, e não de uma ética individual ou individualista, pois, como toda experiência, a experiência de fé só pode ocorrer na intersubjetividade ou no encontro de sujeitos.

\section{Referências}

BAUER, Walter. Orthodoxy and heresy in earliest christianity. Tradução de Paul J. Achtemeier. Filadélfia: Fortress, 1971.

KERN, W. "Heresia”. In: LACOSTE, Jean-Yves (Org.). Dicionário crítico de teologia. São Paulo: Paulinas \& Loyola, 2004. p. 815-816.

KÖSTENBERGER, Andreas; KRUGER, Michael J.; MARSHALL, Ian Howard. The heresy of orthodoxy: how contemporary culture's fascination with diversity has reshaped our understanding of early christianity. Illinois: Crossway, 2010. 


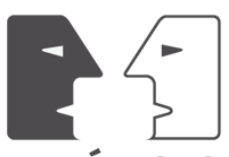

ANTÍTESES

LOSSKY, N. Ortodoxia. In: LACOSTE, Jean-Yves. (Org.). Dicionário crítico de teologia. Vários tradutores. São Paulo: Paulinas \& Loyola, 2004, p. 1299-1300.

RAHNER, Karl. Was ist Häresie? In: . Schriften zur theologie. Einsiedeln: Benziger, 1962. v. 5, p. 527-576.

Recebido em 10/10/2016

Aprovado em 26/03/2018 